\title{
ENTRE PENAS E CORES: CULTURA MATERIAL E IDENTIDADE BORORO
}

\author{
Luis Donisete Benzi Grupioni
}

RESUMO: O artigo analisa uma das formas de afirmação da identidade étnica bororo a partir do estudo da produção material desta sociedade, investigando a oposição existente entre artefatos de uso interno e artefatos confeccionados para venda.

UNITERMOS: Cultura Material - Identidade - Tradição - Bororo

\section{INTRODUÇÃO}

$O$ presente trabalhol ${ }^{1}$ pretende mostrar a afirmação da identidade étnica Bororo presente na cultura material deste grupo, através de uma oposição entre artefatos de uso interno, tradicionais, e artefatos para uso externo, artesanato para venda, analisados no contexto da produção material desta sociedade indígena.

O povo Bororo conta atualmente com cerca de 730 indivíduos (censo/1986) distribuídos em sete aldeias, localizadas num território descontínuo no vale do rio

1 Este artigo foi elaborado dentro do projeto de iniciação científica "Da Cultura material à Organização Social Bororo: possibilidades de um estudo" (1986-87), financiado pela

FAPESP, que também possibilitou a vinda à

São Paulo de Antonio Canajó Kirimida, indio Bororo da aldeia do Meruri - MT, que trabalhou comigo durante um mês no Acervo Plínio Ayrosa - USP, vistoriando a Coleção Bororo. Agradeço às professoras Dominique Gallois, Lux Vidal, Sonia Ferraro Dorta e Sylvia Caiuby Novaes a leitura crítica e sugestões que fizeram a este trabalho.
São Lourenço, no Estado do Mato Grosso. Divididos em quatro reservas, estes Bororo vivem hoje realidades diversas, que vão desde as diferentes situações jurídicas das reservas à relativa heterogeneidade do habitat, passando por diferentes processos de contato, assistência desigual e densidade populacional variada.

A história do contato dos Bororo com segmentos da sociedade nacional aponta para o fato de que, apesar do primeiro contato ser datado de 1718 e das inúmeras perdas culturais a que foram submetidos, os Bororo ainda se mantêm como um grupo étnico coeso e diferenciado, elaborando estratégias específicas de resistência cultural (Cf. Crocker, 1977 e Caiuby Novaes, 1986).

Constituem um grupo étnico no sentido definido por Barth (1969), ou seja, como um tipo organizacional, cuja população se perpetua por meios biológicos, compartilha valores e práticas culturais comuns, compondo um campo de comunicação e interação, onde os membros do grupo se identificam e são identificados por outros indivíduos ou grupos como 
membros distinguíveis de uma mesma categoria. E assim, os Boe, autodenominação deste grupo, consideramse e são considerados Bororo, habitando $o$ que sobrou do seu território tradicional, eles continuam realizando seus ritos, confeccionando seus enfeites, cantando seus cantos, contando seus mitos e fazendo da morte de seus membros um modo de continuar vivendo.

Os ritos funerários e a cultura material Bororo são contextos em que a identidade étnica se afirma. A literatura antropológica sobre o funeral Bororo é vasta e já explorou satisfatoriamente o ciclo funerário e as representações que os Bororo têm a respeito da morte, onde toda a sociedade Bororo se encontra como um todo. Ali se fazem presentes os vivos e todos os mortos que tenham parentes vivos que são por eles relembrados."Pois a morte de um indivíduo desencadeia a necessidade de união em todos os níveis. Esta união é necessária para que a sociedade possa fazer frente às forças centrífugas que a ameaçam, e que tem na morte a sua representação mais concreta." (Caiuby Novaes, 1979:161). Os ritos funerários constituem, assim, um mecanismo de reordenação de uma ordem social comprometida pela morte de um dos membros da sociedade. Os Bororo agrupam-se em torno dos chefes locais, que comandam de modo absoluto todas as atividades ligadas às cerimônias funerárias. Indivíduos de diferentes aldeias deslocam-se para a aldeia onde se realiza o funeral. Ái, formando uma unidade distinta, afirmam "a sua especificidade cultural enquanto conhecedores de práticas mortuárias sui-generis, estigma étnico que congrega os membros da tribo como unidade temporariamente coesa face aos civilizados e às outras sociedades indígenas." (Viertler, 1982:610).
Além do ciclo funerário, a cultura material também constitui um mecanismo de afirmação da identidade Bororo que, agrupando um conjunto de artefatos como "verdadeiros" e um outro conjunto como "misturados", procura demarcar quais artefatos são de uso Bororo interno e quais são feitos por estes para um público externo, ordenando assim as relações dos Bororo entre si e com a sociedade nacional. Pretendemos aqui analisar essas duas categorias empregadas pelos Bororo: "verdadeiro" para o conjunto de artefatos tradicionais, de uso cerimonial, e "misturado" para aquele outro conjunto de artefatos destinados à venda; e ver em que medida estas categorias permitem analisar a cultura material Bororo como um todo articulado à organização social. Para isto, faremos algumas considerações gerais sobre $o$ atual processo de produção material desta sociedade indígena.

\section{TRANSFORMACÕES NA CULTURA MATERIAL TRADICIONAL}

A combinação de diferentes matérias-primas nos artefatos Bororo, retratando entidades naturais $\mathrm{e}$ sobrenaturais, constitui um código simbólico que, diferenciando os diversos artefatos uns dos outros, também os divide entre os vários iedaga-mage, unidades sociais mínimas, que formam a sociedade Bororo. Cada clã Bororo tem um patrimônio específico de bens que é composto por um conjunto de nomes pessoais, cantos, espiritos, representações, seres animais e vegetais e artefatos. Dentro deste patrimônio, os ornamentos, segundo Crocker (1977), têm um papel proeminente: constituem a fortuna do clã, sua propriedade sagrada e os direitos sobre estes bens são defendidos de forma muito zelosa. 
Os artefatos são, assim, confeccionados segundo rígidas normas estabelecidas pela tradição, que determina qual matéria-prima deve ser usada, a combinação de cores, e as técnicas de confeç̧ão, que são observadas pelo artesão por ocasião da manufatura. Determina também quem pode confeccionar, assim como o local e a época certa para a confecção de determinados artefatos.

Vários artefatos são confeccionados somente por ocasião da realização de determinadas cerimônias e rituais, como, por exemplo, o kiogwaro (enfeite de occipício) para a nominação e o aroe e-kuie powari (instrumento musical de sopro) para o funeral. Outros artefatos não estão sujeitos a esta restrição e são confeccionados dependendo da necessidade e da disponibilidade do artesão. E o caso dos trançados (cestos, abanos e esteiras), arcos e flechas, chocalhos, etc.

A confecção de tais artefatos constitui um momento de aprendizagem para os jovens, que observam os processos e técnicas de confecção, ao mesmo tempo em que se introduzem no complexo universo simbólico, que estabelece a combinação de matérias-primas a ser executada na confecção do artefato e 0 seu significado.

A riqueza da cultura material Bororo, longe de ser atropelada pela introdução de objetos indiferenciados dos brancos ou se extinguir em meio à crescente falta de matérias-primas, mantém-se viva e flexível, incorporando e substituindo matériasprimas na composição de padrões clânicos que continuam rigidamente estabelecidos.

É o caso, por exemplo, da crescente presença de penas de pato (turubari) nos artefatos plumários, substituindo as penas brancas do mutum (kuje) ${ }^{2}$, que se tornaram mais raras e dificeis de serem conseguidas em função das alterações do meio ambiente. E também da penugem branca de várias aves, que é colada no ápice das retrizes de araras de certos ornamentos, que foi substituída, em face da dificuldade de se conseguir tais aves, pelo uso generalizado da penugem branca do pato selvagem, ave de maior frequência na área (Cf. Dorta, 1981: 238).

Outro exemplo da substituição de uma matéria-prima escassa por outra de acesso garantido é a substituição de um caracol de carapaça alongada, boro, em certos artefatos por conchas, atu. "Esse é atu, mas está fazendo de boro" (entrevista com Canajó, em 1986). Este tipo de substituição deve ser entendido dentro de um quadro contextual, onde se relacionam o artesão, um conjunto de matérias-primas existentes e a "necessidade" de confecção do artefato segundo rígidos padrões. Esta substituição de uma matéria-prima não existente na área por outra não ocorre de modo vago e generalizado, mas obedece a uma série de regras codificadas, como mostrou Dorta (1981) em relação aos materiais utilizados na confecção do pariko ${ }^{3}$.

De um lado, essa substituição resguarda as matérias-primas mais valorizadas e, de outro, limita o acesso e a usurpação dos diferentes patrimônios clânicos. No nível das representações, mantém-se que a matéria-prima empregada não é a correta, mas substitui aquela que deveria ser. Canajó, do clã dos

2 "Está usando turubari porque não tem pena de kuje". (Canaj6, 1986)

3 Adorno de cabeça em forma de diadema semi-circular, apresentando grande número de penas de araras justapostas sem intervalo. $\hat{E}$ usado na altura do vértex com os atilhos amarrados no occipício. 
Bokodori Ecerae, referindo-se a um brinco do clã dos Aroroe, nabure ao (pele seca da cabeça da ararapiranga onde há um cordel para prender o brinco à orelha), disse: "ele não tem couro. Quando tem, tira o couro da cabeça, com pena. Aí seca e faz o brinco. Agora não tem, então faz com entrecasca." (entrevista em 1986).

A redução dos territórios e a diminuição das espécies animais fornecedoras de matérias-primas indispensáveis à confecção de certos ornamentos fazem com que vários itens da cultura material Bororo não sejam mais confeccionados, como, por exemplo, vários pregos de cabelo, boe e-kiga. Isto acontece porque determinadas matérias-primas não entraram no código de substituição. E o caso das penas de japu 4 , principal matéria-prima utilizada na confecção de certas viseiras, e das penas de gavião real que são usadas na confecção de certos adornos de cabeça. Quando isso ocorre, os artefatos deixam de ser produzidos. A não confecção de certos artefatos por um longo período de tempo acaba por levar a uma perda desse artefato, uma vez que a sua não confecção implica na não reciclagem deste na memória dos velhos $\mathrm{e}$, conseqüentemente, no seu não conhecimento por parte dos jovens.

Apesar de uma série de ferramentas tradicionais terem sido substituídas por objetos civilizados, cuja superioridade técnica é reconhecida e cobiçada pelos Bororo, isso em nada transformou o estilo dos objetos, que continuam a ser executados de acordo com os cânones da tradição Bororo. Agora usam tesouras de metal, agulhas, plainas, alicates, ao invés de conchas de

\footnotetext{
4 As penas de japu foram substituídas na confecção do pariko, conforme mostrou Dorta(1981), por lascas revestidas com pena de arara.
}

madrepérola, ossos e dentes de animais, que em outros tempos davam conta de certas tarefas técnicas básicas como cortar, plainar, lixar, raspar, furar e juntar materiais dos mais diversos.

Agregue-se a isto, a substituição dos fios de algodão nativos pelo uso generalizado da linha de algodão industrial, que é usada em praticamente todos os objetos, amarrando e prendendo matériasprimas diversificadas. A forma de amarrar, prender, juntar, torcer, continua sendo a mesma de antigamente, numa evidente demonstração da continuidade do estilo tradicional apesar da incorporação de materiais "civilizados".

\section{PERDA E PERMANÊNCIA NA CULTURA MATERIAL}

O contato leva, também, à perda de certos itens da cultura material. Além das ferramentas, há o desaparecimento do uso de recipientes em argila em quase todas as aldeias Bororo e a conseqüente perda de técnicas de confecção da cerâmica por parte das mulheres. Isso nos coloca diante da substituição de um artefato de trabalhosa confecção e fragilidade por objetos industrializados dos mais diversos: panelas de alumínio, latas e vasilhames de vidro e de plástico. Graburn (1979:11), analisando a competição das artes tradicionais com os produtos manufaturados, constata que "Artes utilitárias, tal como sacolas e recipientes, são freqüentemente os primeiros a desaparecerem: se suas principais funções são antes utilitárias que estéticas e rituais, eles são substituídos por outros mais leves $\mathbf{e}$ fortes." Entre os diversos tipos de cerâmica, a aria, maior cerâmica confeccionada pelos Bororo, continua em uso durante os ritos funerários, 
embora tenham sido substituídas no uso cotidiano por panelas de alumínio.

Um levantamento superficial dos artefatos tradicionais Bororo, isto é, aquele conjunto de artefatos confeccionados para uso interno, exclusivo da sociedade Bororo, nos levaria a delimitar três conjuntos de artefatos:

- uma série de artefatos que não são mais confeccionados e usados pelos Bororo há um certo período de tempo; - outros que muito raramente aparecem sendo envergados por alguns indivíduos em determinadas cerimônias; - e, por fim, um conjunto de objetos que continuam presentes de modo sistemático no cotidiano Bororo.

No primeiro conjunto de objetos, isto é, aqueles que já não são usados, destaco: o cinto feminino, kogu; adornos labiais, boe eokuadawu; certos pregos, boe e-kiga; certos brincos, boe e-biadawu; entre outros.

Compondo uma segunda categoria intermediária, há um outro conjunto de objetos que esporadicamente são confeccionados e aparecem em uso através de alguns individuos. É o caso de uma série de brincos, boe e-biadawu; das narigueiras, boe enotadawu; de certos colares, boe e-kuie; das braçadeiras, boe e-kana kajejewu; de certos cintos, boe e-kajejewu; do estojo peniano, bá.

No último grupo, penso nos diademas de penas, pariko; certos instrumentos musicais, akodo; certos colares, boe e-kuie; adornos para o occipício, kiogwaro; certos pregos, boe e-kiga; certos arcos, boeiga; certas flechas, tugo; trançados, boe ekudawu e a pintura corporal.

Tal levantamento carece de maior precisão, através de um exame mais sistemático que delimite um período de tempo e um espaço determinado (uma ou mais aldeias), para que se efetue um inventário mais profundo e complexo, especificando todos os itens da cultura material Bororo (cada artefato em particular, como o colar de dentes de jaguar, adugo ó), e não trabalhando com categorias de objetos (conjunto determinado de artefatos, como colares, boe e-kuie), conforme utilizamos aqui. Entretanto, para o nosso objetivo, tais categorias são adequadas, uma vez que pretendemos uma visão geral da cultura material Bororo, onde fica evidente uma presença diferenciada de artefatos no cotidiano Bororo, aqui compreendendo também os momentos rituais, e nos coloca a questão de porque alguns artefatos permaneceram em uso e outros foram abandonados, e quais as implicações disto no nível de toda a cultura material Bororo. Responder a tais questões exige esse levantamento de cada item da cultura material da forma como foi sugerida acima, o que não se enquadra nos objetivos deste trabalho. Entretanto, interessa-nos fazer algumas considerações gerais sobre o assunto.

Graburn (1979:13) coloca que a persistência das artes tradicionais e das habilidades dependem de um conjunto de fatores, a saber: "demanda contínua pelos itens, disponibilidade de matériasprimas tradicionais, tempo de trabalho e ausência de atrações competitivas, conhecimento das habilidades e prestígio dos membros do seu grupo de iguais, o papel destes itens no suporte de sistemas de crenças e sistemas de troca de presentes rituais." Deste conjunto, destacamos alguns itens que nos parecem mais significativos para entender o caso Bororo.

A primeira vista, podemos explicar a permanência de certos artefatos Bororo pela disponibilidade de determinadas matérias-primas e pela exigência de certos objetos para a realização de determinadas atividades 
como, por exemplo, do chocalho, bapo, para a execução de certos cantos, ou dos zunidores de madeira, aije, para a representação dos aije doge aroe durante o funeral, e também pela funcionalidade de outros, como,por exemplo, das esteiras, dos abanos e dos cestos, fabricados principalmente com folhas de palmeira de buriti e babaçu, atividade exclusivamente feminina.

Berta Ribeiro (1983-A:20) escreve que os artefatos são "em si um signo de comunicação cujas potencialidades só podem ser descobertas através de estudos acurados sobre as representações mentais dos grupos que os detém. E ao mesmo tempo uma expressão do ideal estético de um grupo indígena, de personalização do indivíduo e de singularização étnica". Investigando os objetos a partir do seu significado semântico, isto é, enquanto um código de linguagem, percebemos que nele estão combinados matérias-primas que, simbolizando entidades naturais e sobrenaturais, relacionam os objetos aos clãs e aos indivíduos portadores de tais objetos. "Quase todos os objetos são brasonados duma maneira que permitem identificar o clã e o sub-clã do proprietário"

(LeviStrauss, 1955:219). É neste sentido que Crocker afirma que "os ornamentos são emblemas nominais dotados da mesma capacidade de diferenciar, de classificar e de hierarquizar que os nomes próprios. Constituem, assim, uma espécie de "segunda pele" pela qual o indivíduo manifesta sua identidade original (...). Os ornamentos criam para os Bororo um meio paralingüístico de fazer ver ou de exibir sua participação em uma espécie social, um clã, um subclã ou um grupo de nomes. Criam também, coisa que nem as palavras nem os nomes podem fazer, os operadores iconográficos com os quais a identidade pode ser fisicamente expressada, cambiada e transformada nas relações sociais" (1977: 186).

E possível, portanto, pensarmos

numa leitura da organização social Bororo através dos objetos, pois neles estão inscritas e representadas, através dos emblemas clãnicos, as unidades sociais básicas que compõem o todo social Bororo ${ }^{5}$. Através de tais objetos, uma série de relações é travada, como é o caso da confecção, armazenamento, circulação, uso e destruição de um pariko, conforme nos esclarece Dorta (1986-A). Referindo-se à confecção de um pariko aroe, objeto símbolo que é confeccionado para lembrar e substituir um morto, diz a autora: "O processo de confecção é altamente formalizado: a mulher, com a matéria-prima $\mathrm{e}$ os instrumentos em sua casa, coloca-os num abanico-bandeja, entregando-o a seu marido; segurando-o com as duas mãos, solenemente, o inodówo leva-o à casa-dos-homens, passando-o ao irmão da esposa, o dono do diadema que será feito. Este, por sua vez, entrega-o ao iadu do morto que será lembrado através do adorno. Para auxiliá-lo na manufatura, este iadu congrega todos os iadu-mage de parentes falecidos da mulher, isto é, homens do clã da metade do inodówo, todos da metade oposta a do morto. Isto nos remete à constatação de que a manufatura de pariko de aroe é de alçada coletiva, expressando solidariedade" (1986:9) 6 .

Tendo em mente o fato de que os objetos são a expressão material de feixes de relações sociais que são travados entre membros de clãs $e$ metades diferentes, absorvidos em

5 "People of small societies have usually maintained their social subdivisions with material symbols and paraphernalia, often in the form of clothing and ritual objects. " (Graburn, 1979:24)

6 Inodówo (ZH) - marido da irmã. / Iadu substituto social de um defunto antigo. 
relações de caráter cerimonial e envolvendo a expressão do ideal estético desse grupo e considerações a respeito dos padrões de conduta humana, podemos sugerir uma explicação mais completa para a permanência de alguns objetos $e$ a perda de outros, e para o surgimento de uma produção artesanal voltada para o "mundo dos brancos", constituindo um novo campo de comunicação entre agentes de uma nova ordem social, não mais restrita à sociedade Bororo, mas entre esta e a sociedade envolvente.

\section{A DINÂMICA DA CULTURA MATERIAL}

Ampliemos, então, a partir das considerações feitas a respeito do pariko, a nossa reflexão sobre a permanência e a perda de certos itens da cultura material Bororo. A nossa hipótese é de que a tendência deste processo é a permanência de certos artefatos que impliquem num maior grau de complexidade de relações sociais e rituais. Outros artefatos desaparecem quando sua confecção, uso e guarda estão mais restritos ao âmbito individual e/ou familiar, cuja matéria-prima empregada se torne rara e ocorra a perda do significado do artefato ou da cerimônia a ele vinculado.

Neste sentido, o conjunto de artefatos ligados ao funeral, visto como um dos momentos de afirmação da identidade étnica e de reorganização social, estaria propenso a continuar existindo, por implicar no estabelecimento de relações entre um número considerável de indivíduos $\mathrm{e}$ numa atualização do corpus míticocosmológico desse grupo. E também porque alterações nos artefatos implicam em alterações na dinâmica do próprio funeral.
A nominação, assim compreendida, também seria um outro momento de continuidade de certos itens da cultura material, como o kiogwaro e o boe e-tao bu (adorno de cabeça), vista a sua importância enquanto ritual que propicia a associação de indivíduos às unidades mítico-ancestrais, ou seja, aos iedagamage, unidades básicas de toda a organização social Bororo. Este ritual permite o reconhecimento, por parte da sociedade Bororo, da inclusão de um novo membro em seu contingente.

A evolução deste processo poderá levar à eleição de artefatossímbolos que, além de todos os significados e implicações próprias, teriam a função de manter o sistema funcionando, mesmo que seja em termos reduzidos. Teríamos, assim, um conjunto de artefatos, que obrigatoriamente representaria todas as unidades sociais significativas, marcando as diferenças entre elas.

Por outro lado, é possivel pensar num processo de simplificação de certos emblemas clânicos, como acontece com o pariko, para continuar usando o mesmo exemplo, procurando explorá-lo sob diversos pontos de vista. Segundo mostrou Dorta(1986-B:04), o pariko é, na quase totalidade de seus exemplares, composto por três fieiras, das quais " a segunda é a mais significativa, pois é aí que se assentam insígnias clânicas, manifestas através da representação de entidades naturais e sobrenaturais do patrimônio da unidade social de origem". Entretanto, além da segunda fieira, em alguns casos é preciso observar a existência ou não de penugem na primeira fieira $e$, no verso da primeira fieira, a combinação de retrizes de arara. Aí apresentam, às vezes, outras combinações, uma vez que as retrizes de certas araras apresentam duas cores(uma de cada lado da pena) e podem assim ser combinadas tanto na frente como no 
verso. $E$ após olharmos tudo isto que se poderia determinar a qual iedagamage pertence o pariko em questão. Entretanto, com a dificuldade de se conseguir retrizes de arara em número suficiente para atender a todas as exigências de combinação e disposição das penas nos artefatos, os Bororo têm deixado de considerar a combinação no verso, levando em consideração apenas a segunda fieira, numa simplificação do emblema clânico que, de um lado, atende à falta de matérias-primas $\mathrm{e}$, de outro, mantém ainda de modo preciso a identificação do objeto (Cf. Dorta, 1981).

Com essas considerações, pretendemos mostrar a riqueza e a flexibilidade da cultura material Bororo, em conseguir dar conta de todas as transformações a que se vê submetida pelas condições atuais. Devemos lembrar que, apesar da rigidez dos padrões de identificação clânicos presentes nos objetos, estes apresentam variações no decorrer do tempo e também com relação às diferentes aldeias. Retomemos, aqui, algumas características da cultura: "A cultura não é algo dado, posto, algo dilapidável também, mas algo constantemente reinventado, recomposto, investido de novos significados." (Carneiro da Cunha, 1979:36).

A cultura "constitui portanto um processo pelo qual os homens orientam e dão significado às suas ações através de uma manipulação simbólica que é atributo fundamental de toda prática humana. Nesse sentido, toda análise de fenômenos culturais é necessariamente análise da dinâmica cultural, isto é, do processo permanente de reorganização das representações na prática social, representações estas que são simultaneamente condição e produto desta prática." (Durham, 1977:34).
Assim, as variações e transformações observadas na cultura material Bororo não devem ser entendidas como perdas, mas como uma forma de recriação cultural de um grupo, que em face de certas circunstâncias adversas, procura a melhor estratégia. Reinventando, recompondo e substituindo certas matérias-primas, os Bororo conseguem manter o funcionamento do seu sistema material.

\section{CARACTERIZAÇÃO DO ESTILO BORORO}

Em função do que foi exposto, é possível falarmos na existência de um estilo Bororo presente nos artefatos produzidos por esta sociedade. Estamos entendendo por estilo a estabilidade de certos procedimentos técnicos conjugada com a habilidade e familiaridade no emprego de um conjunto de matérias-primas (Cf. Schoepf-1971) 7 .

Dorta (1986-A:227) caracteriza a plumária Bororo pela marcante tendência para a utilização de penas longas de aves de grande e médio porte e pelas elaboradas associações de materiais diversos, criando efeitos de grande beleza e suntuosidade. Caracteriza-se pelo emprego de penas de diferentes formas, cores e dimensões, combinadas harmoniosamente entre si e com outros elementos, tais como cabelos humanos, madrepérola, metal, folíolos de palmeiras, acúleos de ouriço, linha de algodão, couros de mamíferos.

\footnotetext{
7 Daniel Schoepf ao caracterizar a plumária dos índios da Amazônia afirma existir uma certa uniformidade, derivada "... de l'exploitation d'un fonds relativement commun de matériaux et de techiques de fixation ou d'assemblage" (1971:33)
} 
Nos adomos corporais, numerosos e diversificados, as penas são montadas em armações feitas de varetas, fasquias de taquara, cordéis e trançado, que variam de acordo com o tipo do artefato e a região do corpo que será aplicado. A par destes, compõem a plumária diversas categorias de objetos: armas, trançados, instrumentos musicais, brinquedos. Os Bororo enfeitam, também com penas, o crânio e os ossos dos mortos e cilindros cerimoniais de talos de caeté e buriti. Colam-nas, ainda, diretamente sobre o corpo humano, sob a forma de engenhosos motivos decorativos." Caberia ampliar essa caracterização para outros itens da cultura material Bororo. Além das matérias-primas já citadas, temos: ossos, unhas e garras de mamíferos, madeiras de várias espécies, resinas, corantes, cabaças, etc. Quanto às técnicas predominam a amarração, a colagem, o trançado e a justaposição de materiais diversos.

O uso destas matérias-primas e destas técnicas caracteriza um estilo Bororo presente nos artefatos tradicionais, que num certo sentido, dá conta também dos artefatos feitos para a venda, mas, em outro, não permite que as diferenças entre estas duas produções se manifestem. "A existência de um " estilo " estaria assim condicionada à estabilidade da forma daqueles artefatos de uso socialmente reconhecido por um grupo. A estabilidade das formas dependerá, por sua vez, da manutenção de uma boa técnica, ou, em alguns casos, da familiarização com o tratamento de determinados materiais." Frota (1981:37). É nesse sentido que podemos continuar pensando num estilo Bororo para os artefatos de artesanato, aqui definidos como aqueles destinados à venda que, lidando com as mesmas técnicas de confecção (amarração, trançado,...), compõe um único conjunto: o da produção material da sociedade Bororo.

Entretanto, ao aprofundarmos o estudo dos artefatos feitos para venda, percebemos que as combinações dos diversos materiais não correspondem a nenhum dos padrões clânicos comumente encontrados nos artefatos tradicionais e que, portanto, não seguem o mesmo padrão decorativo destes artefatos. A partir daí, o especialista poderia determinar uma separação na cultura material Bororo. De um lado, uma série de artefatos vistosos, combinando de maneira suntuosa certas matérias-primas, "empregando penas longas de aves de grande e médio porte", trançando, amarrando e colando materiais num grau técnico de rara perfeição. E de outro, um conjunto de artefatos marcados pelo emprego de matériasprimas de fácil acesso como cabaça, penas de pato, galinha, periquito, algodão, madeira, folíolo de palmeira, espinho de ouriço-caxeiro; coladas, amarradas ou trançadas em diferentes combinações;caracterizando uma produção em série, de pequenos artefatos (brincos, flautas, espanadores) em sua maioria.

\section{O SURGIMENTO DO ARTESANATO PARA VENDA}

Saindo do plano de análise morfológica e penetrando no universo simbólico dos Bororo, percebemos que a distinção realizada pelo especialista, a partir da análise tecno-morfológica, corresponde a certos critérios de classificação que os Bororo levam em consideração para ordenar seu mundo. Os Bororo classificam um conjunto dado de artefatos como "coisas de boe", "de verdade" e um outro conjunto (o de artesanato) como "coisas pra brae" (branco), 
"misturado". Tal distinção como pretendemos mostrar se efetua na prática através de dois tipos de produção, que seguem canais completamente diversos, mesmo se valendo das mesmas técnicas de confecção e de um conjunto de matérias-primas comuns. $\mathrm{E}$ aqui encontraremos um nível de rigidez impressionante, pretendendo marcar de

\section{ARTEFATOS TRADICIONAIS}

\section{Destino interno}

Envolve um campo de relações que extrapola o âmbito doméstico, estabelecendo relaçð̄es entre individuos de clãs e metades diferentes (esfera coletiva).

Segue um conjunto restrito de regras decorativas ditadas pela tradição, envolvendo uma série de emblemas clânicos. $O$ padrão decorativo identifica cada clă Bororo

A confecçãode determinados objetos implica no pertencer a determinadas categorias sociais, havendo uma divisão sexual do trabalho precisa

Uso preciso de um conjunto de matérias primas, empregando longas e vistosas penas de certas aves específicas

Exigencia na qualidade da confecção dos artefatos, que são controlados pela sociedade

Produção voltada para certos acontecimentos.

A confecção, uso e guarda dos artefatos tradicionais está regulada por normas específicas que são seguidas pelos indivíduos e submetidas a sanções sociais. Tais sanções ocorrem modo preciso os artefatos de uso interno $e$ os artefatos para venda, destinados ao mercado consumidor que, em termos de artesanato indígena brasileiro, é ainda restrito.

Passemos ao quadro de oposiçб̃es entre estas categorias e, em seguida, à sua explicitação:

\section{ARTEFATOS DE ARTESANATO}

Destino externo

A produção, venda e os beneficios advindos dessa comercialização limitam-se aos moradores de uma determinada casa (esfera familiar)

Apresenta um conjunto amplo de possibilidades decorativas limitadas pela matéria prima e técnicas de confecçăo (criatividade em cada objeto). $O$ artefato identifica a sociedade como um todo, através do estilo

Todos os individuos podem confeccionar quaisquer objetos, assim como algumas tarefas podem ser desempenhadas indiferentemente do sexo

Grande mistura de matérias primas, empregando, por exemplo, na maioria dos objetos penas de várias aves

A qualidade da confecção do artefato fica a juizo de cada artesão, não havendo um controle da sociedade sobre essa produção. Este controle é exercido fora da sociedade.

Produção em série.

no sentido de impedir a confecção inadequada dos artefatos, quer por desleixo do artesão ("o trançado está de qualquer jeito"), quer por uso inadequado da matéria-prima ("boe não 
faz com pena de amarelo"); ou por estar sendo feita por quem não tem direito ("nas coisas de verdade, de boe, só pode fazer se o dono mandar." Canajó, 1986).

O funeral constitui o momento onde um indivíduo determinado passa ter o direito de "mexer" com o patrimộnio de um outro clã que não o seu. É quando o aroe maiwu, representante social do morto, após caçar e entregar o animal aos parentes do morto, recebe como retribuição, mori, "arcos e flechas cerimoniais, um Powari Mori (instrumento musical de sopro), nomes que pertençam ao patrimônio de nomes do clã do morto, a possibilidade de fazer ornamentos com padrões decorativos privativos daquele clã e eventualmente, uma mulher nova com quem ele poderá se casar." (Caiuby Novaes, 1979:176). Assim, essa possibilidade de manusear espécies clânicas privativas de um outro clã só ocorre nesta situação determinada, conforme exemplifica Canajó a partir do clã dos Apiborege: "Apiborege faz tudo que tem, e aí enfeita aquele que matou. Aí entrega flecha, buke (rede), labrete. Chama ele de iadu (representante social de um defunto antigo). Só pode usar (tais objetos) quando fez morice. Aí Apiborege fala: pode ocupar, fazer, que eu mando. Aquele que não matou nada, não faz nada." (Canajó, 1986). Não faz nada de outro clã, a não ser do seu próprio clã, ou do de sua esposa em determinadas situações.

Um indivíduo do clã dos Bokodori Ecerae confeccionou um kiogodo $^{8}$ do clã dos Baado Jebage

8 "Kiogødo- Kiogo,ave; odo,bico (prego pontiagudo como bico de aves). É uma simples vareta revestida de plumas coladas em mosaico e encimada por um tufo de retrizes de araras. É privativa dos clãs Baádo Jebage Cebegiwuge ou dos Baado Jebage que foi incorporado ao Acervo Plínio Ayrosa do Depto. de Ciências Sociais USP. Na ocasião da confecção, sua mulher disse que se alguém 0 visse confeccionando aquele artefato, aquilo poderia ser motivo de muita briga, uma vez que ele não tinha adquirido o direito de confeccionar tal objeto. Entretanto, em função do dinheiro que conseguiria com a confecção de tal artefato, este Bororo efetuou a transação. Retomemos as conclusões de Caiuby Novaes, quando em sua análise situacional do grupo doméstico Bororo afirma que "embora haja uma norma ideal de conduta, na prática ela é manipulada para atender ao interesse das pessoas que vivem estas situações. A existência de uma norma ou princípio estruturador não implica em que a realidade social empiricamente observada seja uniforme e em contrapartida, esta falta de uniformidade não implica em ausência de normas de conduta, e nem no seu desconhecimento por parte dos agentes sociais." (1979:36).

Por outro lado, a confecção dos artefatos destinados à venda não segue regras estipuladas pela tradição, ou melhor, segue regras de outra natureza. Podemos dizer que, de modo geral e num primeiro momento, todos os artefatos confeccionados com a intenção de serem vendidos apresentam variações que não correspondem aos rígidos padrões clânicos. Às vezes, pequenos detalhes dão conta de estabelecer a diferença entre um artefato tradicional, de uso interno, e um outro feito para a venda, como é o caso, para citarmos alguns exemplos, de uma flauta: parira kujagureu',

Cobugiwuge, de acordo com a cor das penas e das cores." (E.B.- 1, 1962: 342/343) 9 É uma espécie de flauta, confeccionada a partir de "dois gomos de taquara contendo um nó, perto do qual se abre a embocadura à guisa de tubo de orgão. Produz um som de 
confeccionada de acordo com a tradição Bororo, ou seja, completamente revestida de plumas vermelhas de ararapiranga, Ara macao, com tufos anulares de plumas brancas de mutum, Mitu mitu, e que estando assim confeccionada, seria privativa do sub-ciã dos Kie Cobugiwuge. Entretanto, esta apresenta um tufo anular numa das extremidades da flauta de pena de galinha, que a desqualifica como um artefato de uso interno, uma vez que aí está introduzido um elemento diferenciador e estranho ao sistema de emblema clânico, embora seja estruturalmente necessário ao conjunto da cultura material Bororo. Diriam os Bororo ao inspecionar este artefato que ele "não está certo", "não é de verdade", "está fazendo isso para vender".

Antonio Canajó, informantemor de vários antropólogos e profundo conhecedor da cultura Bororo, ao inspecionar um prego de cabelo, boe ekiga, do Acervo Plínio Ayrosa, que estava classificado como bakuguma oiaga, prego com uma retriz de gavião requinte, do clã dos Aroroe Cebegiwuge, afirmou que aquele prego não era de clã, mas feito para vender: "é para vender, não tem ponta. É para vender, ele não precisa de ponta para enfiar. Está brincando." (Canajó, 1986). Com referência a outro prego de cabeça, ele disse: "se é de uso, vai ter ponta, e vai ter aro (pena) pendurado. Aqui ele faz de madeira, de uso mesmo, ele faz de osso de buke (tamanduá)." (Canajó, 1986).

Poderíamos citar vários outros exemplos em que um artefato apresenta, praticamente, todas as características de um clã, mas que, entretanto, traz um elemento estranho ao conjunto, que o "desqualifica" enquanto um artefato de uso interno, congregando-o na categoria de objetos para venda. Esta seria uma primeira categoria de artefatos confeccionados com o intuito da venda.

Um segundo grupo de artefatos destinados à venda é composto por aqueles objetos mais facilmente identificáveis como objetos de artesanato. De um lado, teríamos aqueles artefatos cujo modelo é tirado do conjunto de artefatos tradicionais, mas que são retrabalhados com um novo tipo de decoração, com uma modificação no tamanho ou com uma evidente perda de detalhes técnicos na confecção do artefato. Este seria o caso das flautas, tangas, chocalhos, instrumentos musicais de sopro confeccionados a partir de uma cabaça, colares, coroa de penas para a cabeça, os arcos e flechas miniaturizados. As flautas são decoradas basicamente com folíolos de palmeira, pintura de urucum e linha de algodão. Algumas apresentam um trançado com espinho de ouriço, outras com alguma decoração em penas. Os chocalhos são geralmente decorados no cabo, utilizando-se dos mesmos materiais. Seu som, entretanto, em nada se assemelha aos bapo, chocalhos usados durante a execução dos cantos Bororo. Percebe-se um uso variado de penas coloridas em todos estes objetos. "E para vender, está todo misturado ... aquele que compra quer coisas colorida, para ficar bonito. Então faz grande, vende mais caro." (Canajó, 1986). Vemos aqui a preocupação do artesão em confeccionar um objeto que atenda aos interesses da demanda consumidora.

Teríamos ainda aqueles artefatos cuja inspiração do modelo é claramente externo à sociedade Bororo, como os espanadores de penas ou de rabo de tamanduá, os anéis de 
tucum, os prendedores de cabeto 10 . Aqui, de modo mais evidente, nota-se as influências externas condicionando a produção de certos artefatos.

Devemos agora examinar a questão da criatividade artística com relação à produção material desta sociedade. Acredito não ser possível pensarmos em criatividade do artesão Bororo ao confeccionar um artefato de uso tradicional, cerimonial, no qual ele deverá prestar atenção a uma série de normas estabelecidas pela sociedade, e que exige do artesão fidelidade $\mathbf{e}$ destreza em executar de forma correta e rígida a confecção de determinados artefatos. 11 Longe de se esperar do artesão que ele crie elementos decorativos novos, espera-se dele 0 cumprimento dos padrões tradicionais, que estão sempre referidos aos diversos

10 Berta Ribeiro (1977) numa visita à loja da Artíndia no Museu do Indio, no Rio de janeiro, em novembro de 1976, informa sobre alguns artefatos que lá estavam para serem vendidos: "Os Bororo fazem armas, colares, instrumentos musicais (flautas e maracás) e diversos utensílios, como estacas de cavar. Chamou-nos a atenção a existência de uma espécie de espanadores em miniaturas feitos com penas de diversas aves que não vimos nas coleções desses índios que, aliás, são grandes plumistas. " (77) Disto concluímos que esta produção diferenciada não é recente, tendo no mínimo dez anos. Há, ainda, informações sobre a existência desta produção, que datam de mais tempo: alguns artefatos Bororo produzidos especificamente com o intuito da venda, fazem parte da Coleção do Instituto de Educação, depositado no Acervo Plínio Ayrosa da USP, datando de 1937.

11 Escreve Darcy Ribeiro (1986:30): "O público do artista indígena, seu corpo de apreciadores e críticos, é a comunidade total que exerce sobre ele uma grande pressão. Por outro lado, um ingente reclamo de perfeição formal; e por outro, uma clara exigência de fidelidade dos padrões tradicionalmente estabelecidos." clãs que compõe a sociedade Bororo. A criatividade aqui deve ser pensada a nível do processo de elaboração da cultura material tradicional que estabelece limites e fronteiras a serem respeitadas pelos artesãos em seus trabalhos. $\mathrm{O}$ artesanato, ao contrário, por não estar submetido às regras deste sistema clânico, permite a manifestação da criatividade dos artesãos na escolha das matérias-primas e na execução de motivos decorativos dos mais diversos, confeccionando objetos diferentes, adaptados ao consumo externo. 12

Devemos construir o espaço em que a criatividade do artesão Bororo se manifesta: de um lado ela está restrita a um certo conjunto de matérias-primas, ao conhecimento tecnológico do grupo e, de outro lado, não estando sujeito aos padrões impostos aos artefatos tradicionais, pode o artesão elaborar as mais diversas combinações, imprimindo a sua "marca", o seu gosto estético ou - do seu suposto comprador, dependendo do contexto.

$\mathrm{Se}$ os artefatos de uso tradicional tendem a criar um campo vasto de interação entre os indivíduos de clãs e metades diferentes, quer na confecção, uso ou guarda dos objetos, como mostramos páginas atrás, 0 artesanato tende a ficar restrito ao âmbito doméstico, intensificando a relação dentro das casas, entre marido, mulher e filhos. $O$ homem e a mulher dividem algumas tarefas relacionadas com a confeç̧ão dos artefatos para venda: o homem é o responsável pelo abatimento das aves, de onde saem as penas, usadas em larga escala nos objetos para comércio; pela obtenção da taquara para as flautas; e a mulher por sua vez é quem elabora a decoração das flautas, faz a junção das

12 Segundo Graburn (1979:15) os objetos feitos para venda devem ser (a) baratos, (b) portáteis, (c) inteligíveis, d) limpáveis (dustable), e algumas vezes (e) utilizáveis. 
penas na elaboração dos espanadores, brincos, chocalhos, etc. Estas tarefas, entretanto, também podem ser executadas pelos homens. A transação comercial é na maioria das vezes executada pelo homem.

Se a confecção dos artefatos tradicionais implica num trabalho exclusivamente masculino, com exceção do trançado, única categoria de artefatos tradicionais que é confeccionada pelas mulheres 13 , o artesanato, ao contrário, incorpora as mulheres nesta produção, inclusive na confecção de arcos e flechas

Lembremos que o artesanato representa o principal meio de acesso aos bens industriais dos brancos. "... deve-se admitir como realidade irretorquível a motivação indígena de produzir bens artesanais para troca por bens industriais $e$, até mesmo, bens suntuários, assim como a existência de um público comprador nacional $\mathrm{e}$ internacional, cada vez mais interessado na aquisição de produtos artesanais indígenas." (Ribeiro,B., 1983-B:12).

\section{O ARTESANATO NAS ALDEIAS BORORO}

\section{O artesanato é confeccionado em todas as aldeias Bororo ${ }^{14}$,}

13 O trançado Bororo, de um modo geral, não é quase comercializado. $O$ parikiboto, abanico/bandeja, é,entre os artefatos de trançado, comercializado esporadicamente, enquanto que cestos e esteiras só o são muito raramente. Não cheguei a encontrar nenhum destes artefatos nas lojas de artesanato que visitei, embora algumas mulheres tenham afirmado já terem vendido alguns destes artefatos.

14 Exclui-se deste levantamento as aldeias do Perigara e Sangradouro, que não foram visitadas por nós durante a pesquisa. constituindo uma realidade comum e ao mesmo tempo diferenciada, dependendo da aldeia. Em algumas aldeias, ele é a fonte principal de subsistência; em outras, é uma atividade esporádica e irregular. Às vezes é comercializado diretamente pelos índios, outras vezes a transação se dá a partir de um intermediário.

A especificidade do artesanato com relação às outras atividades econômicas está no fato de que o artesanato é uma atividade sempre garantida, no sentido de que todos os indivíduos podem confeccioná-lo e que, quase sempre, há a possibilidade de comercialização imediata, embora os Bororo possam se valer de excedentes de arroz e peixe em certas ocasiões.

As aldeias do Meruri e do Garças vivem praticamente a mesma realidade quanto à produção de artesanato. Aqui ele constitui a principal fonte de renda dos Bororo, garantindo acesso a uma série de produtos básicos, constituindo-se numa atividade para a qual os Bororo, homens e mulheres, dedicam parte considerável de seu tempo. A maior parte da produção artesanal é trocada com os missionários salesianos por mantimentos como macarrão, café, mate, açúcar, feijão, sal, óleo, molho de tomate, bolacha, $\mathrm{e}$ outros produtos como linha, pilha, bom-bril, sabonete, fumo e sabão.

A Missão Salesiana no Meruri mantém uma loja, onde é vendido o artesanato produzido pelos Bororo do Meruri e do Garças, e também uma cantina, onde são vendidos os produtos acima mencionados, ou trocados por artesanato. Grande parte do artesanato da loja é comercializado em dois postos de venda, em Cuiabá e em Campo Grande( no Museu Dom Bosco), sendo o restante comercializado na própria loja, ou quando algum Bororo resolve ir à cidade e leva alguns objetos para serem vendidos. 
Os preços pagos aos Bororo pela Missão são calculados a partir de dois salários-mínimos, levando-se em conta o tempo médio gasto pelos indivíduos na produção dos artefatos, segundo informações de Mestre Mário Bordignon, salesiano, que também disse que "o pequeno lucro" obtido pela missão é totalmente consumido pelos gastos com a comercialização do artesanato e com a compra de gêneros alimentícios. Ele estabeleceu como meta ideal, uma equivalência entre a venda de artesanato e a compra de alimentos, tanto a nivel da cada família Bororo, como a nível da própria missão.

Os missionários salesianos mantêm um caderno onde é anotado o saldo positivo ou negativo de cada familia Bororo. Uma família tem saldo positivo quando o valor do artesanato entregue à missão é maior que o valor dos produtos e mantimentos retirados por ela da cantina. Este saldo, quer positivo ou negativo, tende a ser pequeno, uma vez que ele é controlado pelo missionário responsável pela troca, que procura a referida equivalência.

Esta troca direta do artesanato por produtos industrializados, usual entre os Bororo do Meruri e do Garças, é entre os Xavante excepcional; estes preferem receber em dinheiro o valor correspondente ao artesanato vendido, para em seguida adquirir o que desejam, segundo nos informa Menezes (1985), que também afirma que a relação das mulheres Xavante "com o dinheiro é de grande recato. Raramente as artesãs se dirigem pessoalmente a loja para oferecer os seus produtos; esta atitude peculiar é própria das viúvas e das mulheres cujos maridos estão ausentes da aldeia. Ainda assim, colocam rapazes solteiros, filhos ou sobrinhos, que se encarregam de completar para elas a transação." $(1985: 494-495)$. Isto não se verifica entre os Bororo da missão, onde homens e mulheres comercializam os produtos de sua atividade artesanal, quer com os missionários, ou com outros agentes dentro da reserva (mascates, turistas, antropólogos,...). As transações realizadas fora do âmbito da reserva, na cidade, são geralmente realizadas pelos homens.

Dentre as aldeias que compõem a sociedade Bororo hoje, a aldeia do Meruri é considerada a mais aculturada de todas. E possível falarmos numa verdadeira crise de identidade desses Bororo, que não só são vistos negativamente pelos Bororo de outras aldeias, como também por indivíduos do próprio Meruri. Por diversas vezes ouvi Canajó referir-se ao fato de que no Meruri não se fabricava mais objetos tradicionais, "coisas de verdade", pois lá não havia mais Bororo e nem faziam funerais. "No Meruri acabou. Não sabe fazer coisas de boe" (Canajó, 1986). É sintomático o fato de que no Meruri, aldeia sob jurisdição salesiana há mais de 80 anos, não haja funeral(os funerais tradicionais de pessoas mortas no Meruri são realizados na aldeia do Garças), a produção artesanal seja muito intensa e, em contrapartida, a produção de objetos tradicionais 15 seja

15 "Vários pariko foram utilizados no decorrer destas cerimônias, e não pertenciam aos Bororo, e sim ao Mestre Mário, que compra as penas de arara e encomenda geralmente para Canajó, a confecção do pariko, o qual guarda e empresta para a execução de alguns rituais. No Meruri, Canajó é o único artesão que sabe fazer "enfeites de verdade", sendo que várias pessoas pedem a ele que faça objetos para elas". (Grupioni, L.D.B. - I Relatório Científico à FAPESP - Projeto de Iniciação Científica: "Da Cultura Material d Organização Social Bororo: possibilidades de um estudo", APA-USP, dat., São Paulo, 1986, pág.36). 
extremamente reduzida. É quase que possível estabelecermos uma equação matemática linear, onde o primeiro termo, crise de identidade, seria igual à somatória de outros termos, como a intensa produção artesanal para venda, reduzida produção de objetos tradicionais, e não realização dos funerais.

$\dot{E}$ interessante fazer notar aqui que, há cerca de cinco anos, iniciou-se no Meruri um processo de resgate da identidade Bororo, patrocinado pelos missionários salesianos, que se traduz na construção do Bai mana gejewu (casa dos homens) no centro da aldeia, no aumento de rituais de nominação e na busca de uma melhor adequação da escola à cultura Bororo.

Os Bororo tentam de certa maneira, atender aos gostos e preferências de seus consumidores, com relação a decoração, quantidade e variedade dos artefatos. Os Bororo do Meruri são os que mais estão sujeitos a estas exigências, uma vez que a maior parte de sua produção artesanal é comercializada com/ou através dos missionários, que incentivam a confecção de determinados objetos dependendo da vazão que conseguem dar aos artefatos estocados na loja da missão, ao mesmo tempo que controlam a "qualidade" dos artefatos produzidos. Por serem intermediários extremamente presentes no cotidiano Bororo, sua influência sobre a produção artesanal é considerável.

A produção artesanal na aldeia do Tadarimana é uma atividade para a qual os Bororo, homens e mulheres, estão continuamente voltados, sendo intensificada quando algum membro da família resolve ir até Cuiabá, onde "o preço é melhor que aqui em Rondonópolis" (entrevista com Eduardinho, 1986), para comercializar o artesanato na loja da Artíndia-Funai ou na Casa do Artesão, mantida pelo Governo do Estado do Mato Grosso, que revendem 0 artesanato com um acréscimo de $40 \%$ do preço pago aos índios. $O$ artesanato pode ser comercializado em Rondonópolis, onde - preço alcançado não é tão bom quanto o de Cuiabá, cuja viagem acaba sendo mais dispendiosa. $O$ dinheiro obtido com a venda do artesanato é imediatamente revertido em alguns bens desejados pela família. "Depois de vender, aí compra alguma coisa que precisa." (Eduardinho, 1986).

Tanto no Tadarimana como na aldeia do Córrego Grande, na Reserva Indígena Teresa Cristina, 0 artesanato não é a principal atividade econômica destes índios; ele representa um meio de acesso a alguns bens industrializados, que não constituem a base da alimentação desses Bororo. A agricultura, a caça e a pesca formam o trio no qual se apóia a subsistência; sendo a caça e a pesca as atividades mais valorizadas.

Dada a distância e a dificuldade de acesso da aldeia do Córrego Grande às cidades mais próximas como Fátima, Rondonópolis e Cuiabá, a venda de artesanato é mais esporádica e, quando ocorre, se faz com um maior número de produtos.

No Piebaga, o artesanato é feito por poucos individuos e esporadicamente, e segundo disseram , só 0 fazem quando há alguma encomenda de algum comprador de fora da área, pois o preço pago pelo artesanato na região não compensa o trabalho gasto. Por um arco e flecha tradicional, conseguem de cem a cento e vinte cruzados; por um arco e flecha enfeitado, uma média de vinte e cinco cruzados em Rondonópolis (em 1986).

De modo geral, os preços alcançados pela venda do artesanato são baixos em relação ao tempo de trabalho e matéria-prima gasto na confecção dos objetos. Isto parece ser uma tendência geral do processo de comercialização do artesanato 
indigena. ${ }^{16}$ Urge um projeto que torne esta atividade mais rendosa para os Bororo, valorizando essa forma de expressão artística, de produção econômica e afirmação étnica. De acordo, portanto, com Berta Ribeiro (1983-b:26), quando ela afirma "que a produção artesanal para fora objetiva a conservação do artesanato para dentro, como símbolo de identidade étnica, de autonomia cultural e econômica e de orgulho tribal."

\section{A AFIRMAÇÃO DA IDENTIDADE BORORO}

Do que foi visto até agora, e o que dá ao caso Bororo uma importância singular, é esta rígida separação entre os artefatos tradicionais de uso interno e o artesanato para venda, que constitui uma resposta à necessidade de se manter uma ordem interna e uma distinção externa. $O$ processo de uma produção diferenciada para dentro e para fora já foi descrito em várias sociedades indígenas, mas a rigidez com que estabeleceram tais diferenças confere ao caso Bororo algo muito particular. 17

16 Média do valor de alguns produtos de artesanato Bororo no comércio local em julho de 1986: flauta...20,00; colar...5,00; enfeite de cabeça...5,00; brincos...5, 00 ; arco e flecha...30,00.

17 a- "A produção de artefatos destinados à comercialização, diferenciados dos objetos de uso dentro da sociedade produtora, não é um fato novo característico de nossa época. Já nos séculos XVIII e XIX, os índios da Amazônia produziam artefatos destinados ao comércio regional e objetos para venda, ao gosto dos colecionadores e viajantes europeus. " in: Identidade Étnica e Sobrevivência, folheto da exposição promovida pela Associação Brasileira de Antropologia e Acervo Plínio Ayrosa-USP, 1982, mimeo.
De um ponto de vista mais funcionalista, o surgimento de uma produção totalmente voltada para o exterior resguarda a cultura material tradicional Bororo das influências externas, resguardando também o patrimônio clânico, indispensável à manutenção da organização social nos seus moldes tradicionais. Uma vez que o artefato indica não só o status do seu possuidor, mas um quadro de relações mais amplo, a perda ou a deturpação desse patrimônio identificador, isto é, as insígnias clânicas, não poderia deixar de afetar todo $o$ conjunto de instituições a ele associado. Por outro lado, fica o artesanato a mercê das solicitações da clientela, do seu mercado consumidor, abrindo a possibilidade do surgimento de artesãos mais habilidosos, que se destaquem dos demais na especialização de um único artefato.

Indaguei meu informante a respeito do fato dos Bororo fazerem uma produção diferenciada para venda, e ele me respondeu que "Bororo antigo não quer vender coisa que ele usa, então faz misturado ... ele não quer

b- Ao analisar a produção artesanal da sociedade Xavante, Claudia Menezes classifica os artefatos em duas categorias: bens produzidos para troca e bens de uso simbólico da sociedade. Entretanto, a autora afirma que "em determinados contextos, esta distinção se anula, uma vez que o acervo sacralizado assume o caracter de mercadoria, como tem ocorrido, por vezes, nas áreas Xavante. Terminado o ciclo cerimonial, por ocasião da festa de iniciação masculina ou outros eventos igualmente significativos, chegam ao mercado regional flautas, enfeites wamnorõ (feixe de seda de buriti semelhante a um capuz), ornamentos indicativos de cargo cerimonial (colares e adornos para a perna, pópara, associado ao Pahori'wa) e flechas rituais que no passado eram preservadas do olhar das mulheres e de estranhos. " (Menezes, 1985:485-486). 
fazer coisas de verdade, porque depois morre, e aí fica as coisas dele aí." (Canajó, 1986). Cabe lembrar que após a morte de um indivíduo todos os seus pertences são destruídos, inclusive a casa em que ele morava. Além do artesão deixar no objeto confeccionado sinais que possibilitam identificá-lo perante os outros artesãos da aldeia, acredita-se que algo da essência do indivíduo fica ali incorporado.

Roberto Cardoso de Oliveira afirma que, no contexto das relações interétnicas, há um sistema de "oposições" através do qual se afirma uma identidade contrastiva, que implica na afirmação de um "nós" coletivo diante dos "outros". "Quando uma pessoa ou grupo se afirmam como tais, o fazem como meio de diferenciação em relação a alguma pessoa ou grupo com que se defronta. E uma identidade que surge por oposição. .Ela não se afirma isoladamente"(1976:05). E além dịsso, ela não pode ser definida em termos absolutos, mas em relação a um dado sistema de identidades étnicas, diferentemente valorizadas em contextos específicos. A identidade é assim, contrastiva e contextual, na medida que implica o confronto com outras identidades em ocasiões específicas. E neste sentido que queremos entender $o$ artesanato Bororo que, se de um ponto de vista não faz referência a nenhum clã específico, de outro, segue um determinado estilo e apresenta a sociedade Bororo como um todo, coesa frente a sociedade envolvente.

$\mathrm{Na}$ situação de contato interétnico não há interesse nem vantagens para a sociedade Bororo em se apresentar segmentada nos diversos clãs que a compõe. Pelo contrário, é muito mais estratégico que ela se apresente como um todo compacto, para fazer frente aos interesses na maioria das vezes antagônicos da sociedade envolvente. Desse modo a divisão em clãs e linhagens, base da organização social, fica restrita à sociedade Bororo, ordenando as relações entre os diversos indivíduos associados aos seus iedaga-mage. E quando esta sociedade se confronta com uma outra, então ela o faz como um todo, acima e apesar das divisões clânicas. E é isto justamente o que acontece com a cultura material: os artefatos tradicionais ficam restritos ao uso interno, divididos entre os diversos indivíduos submetidos a uma série de relações sociais, cristalizadas pela tradição; e os artefatos para venda, indiferenciados quanto a uma filiação mítico-ancestral, apresentam a sociedade Bororo como um todo frente às outras sociedades envolvidas numa relação de contato.

A hierarquia existente entre os clãs, e presente na cultura material através de objetos mais vistosos e mais valorizados, continua a ser um parâmetro de organização interna da sociedade Bororo; entretanto, esta, ao entrar em contato com outras sociedades, garante aos seus individuos possibilidades iguais, não se valendo de tais distinções e diferenciações de prestígio. No contato são os Boe, como um todo de um lado, e os braedoge, brancos, do outro. E como se a divisão clânica deixasse de existir, ou melhor, ela perde a referência por não ser estratégico aos Bororo se apresentarem individualmente como um kiedu ou Bakoro Ecerae, porque tais categorias não têm correspondência nenhuma fora da sociedade. $E$, portanto, elas não são significativas para 0 estabelecimento de certas relações, por não terem sentido.

Se os Bororo e os grupos Gê, de um modo geral, insistem a todo momento na demarcação de fronteiras, quer a nível do privado e do público; do ritual e do doméstico; da floresta e da aldeia; da natureza e da cultura; os 
artefatos, enquanto expressão material desta sociedade, são instrumentos privilegiados para demarcar o que é Kie e o que é Paiwoe; o que é Ecerae e o que é Tugarege; enfim, o que é de uso Bororo, e o que não é Bororo, numa evidente afirmação de sua identidade étnica .

O que nos interessa aqui, é que podendo identificar o estilo de uma sociedade a partir de sua produção material, essa produção pode ser manipulada com vistas a afirmar a identidade clânica e étnica desse grupo. $\dot{E}$ isto que fazem os Bororo ao afirmarem que certos artefatos são brincadeiras, "mentira". Mentiras que uma sociedade produz numa tentativa de continuar coesa face a uma outra sociedade, que a ameaça de todos os lados, que cobiça suas terras, e que quer arrebatar o colorido dos seus enfeites. Mas a esta sociedade, os Bororo dedicam uma parte ínfima de sua criatividade, enquanto a beleza e esplendor permanecem restritos à sua comunidade e ao ciclo funerário, momento épico onde vivos e mortosrepresentados continuam a afirmar as suas verdades eternas. 


\section{REFERÊNCIAS BIBLIOGRÁFICAS}

ALBISETTI, C.E. E VENTURELLI, A.J. - Enciclopédia Bororo, Volume I, Campo Grande, 1962.

BARTH, R. - Ethnic Groups and Boundaries - The social organization of cultural diferences, Little Brown Co., Boston, 1969.

CAIUBY NOVAES, S. - Mulheres, Homens e Heróis, Dinâmica e Permanência através do Cotidiano da Vida Bororo - FFLCH-USP, Série Antropologia, n.8, São Paulo, 1986.

- "As casas na organização social do espaço Bororo" in Caiuby Novaes, S. (org.) Habitações Indigenas, Nobel e Edusp, São Paulo, 1983.

Lourenço", São Paulo, dat., 1985.

- "II Relatório de Avaliação das Áreas Bororo do Rio São

CAIUBY NOVAES, S. E SERPA, P. - Relatório de Avaliação das Áreas Bororo do Rio São Lourenço, São Paulo, dat., 1985.

CARNEIRO DA CUNHA, M. -"Etnicidade: da cultura residual mas irredutível" in Revista de Cultura - CEDEC, ano 1, n.1, São Paulo, 1979.

CROCKER, C. - "Las reflexiones del si (The mirrored self)" in Lévi-Strauss, Claude La Identidad, Ediciones Petrel, Barcelona, 1981 (1977), págs. 175 a 205.

DORTA, S.F. - Pariko: etnografia de um artefato plumário. Coleção Museu Paulista, série Etnologia, vol. 4, São Paulo, 1981.

- "Plumária Bororo" in Suma Etnológica Brasileira - Vol.03 - Arte Índia, FINEP/Vozes, Petrópolis, 1986a.

- Sobre Diademas, Homens e Almas, Curitiba, dat. 1986b.

DURHAM, E.R. -"A Dinâmica Cultural na Sociedade Moderna" in Ensaios de Opinião, n.4, São Paulo, 1977.

FROTA, L.C. - "A cultura material do Indio Brasileiro: um objeto de conhecimento" in FUNARTE - Museu Paraense Emilio Goeldi, Coleção Museus Brasileiros n.4, FUNARTE, Rio de Janeiro, 1981.

GRABURN, N. -"Introduction: Arts of the Fourth World" in Graburn, N. - Ethnic and Tourist Arts: Cultural expressions from the fourth world, University California Press, Berkeley, 1979. 
GRUPIONI, L.D.B. - I e II Relatório Cientifico à FAPESP - Projeto de Pesquisa: "Da cultura material à organização social Bororo: possibilidades de um estudo", São Paulo, dat., 1986.

LÉVI-STRAUSS, C. - "Bororo" in Tristes Trópicos, Edições 70, Lisboa, 1986(1955).

MENEZES, C. -"A produção Artesanal" in Missionários e Indios em Mato Grosso (os Xavante da Reserva de São Marcos), 2 vols., tese de Doutoramento inédita, USP. dat., São Paulo, 1985.

OLIVEIRA, R.C. -"Identidade Étnica, Identificação e Manipulação" in Identidade, Etnia e Estrutura Social, Biblioteca Pioneira de Ciências Sociais, São Paulo, 1976.

RIBEIRO, B. -"O Artesanato indígena como bem comerciável" in Ensaios de Opinião, n.5, São Paulo, 1977.

-"O Indio Brasileiro- Homo faber, Homo ludens" in A Itália E O Brasil Indígena, Fundação Roberto Marinho, Rio de Janeiro, 1983 A.

-"Artesanato Indigena: para que, para quem ?" in O artesão tradicional e seu papel na Sociedade Comtemporânea, FUNARTE, Rio de Janeiro, 1983 B.

-"A Linguagem Simbólica da Cultura Material" in Suma Etnológica Brasileira-Vol.3 - Arte India, Finep/Vozes, Petrópolis, 1986.

RIBEIRO, D. - Os Índios e a Civilização - a integração das populações indigenas no Brasil moderno, Editora Vozes, São Paulo, 4. Edição, 1982 (1977).

Índia, FINEP/Vozes, Petrópolis, 1986.

- "Arte Índia" in Suma Etnológica Brasileira - Vol.3 - Arte

SCHOEPF, D. - "Essai sur la plumasserie des Indiens Kayapo, Wayana et Urubu Brésil" in Bulletin Anuuel du Musée d'Ethnographie de Genêve, 14, Genêve, 1971.

VIDAL, L. - "A Estética dos Índios" in Ciência Hoje, vol. 4, n. 21, São Paulo, 1985. 